\title{
Histopathology of intestinal inflammation related to reactive arthritis
}

\author{
C CUVEliER, C BARBAtis, h MiElants, M DE VOS, H ROELS, \\ AND E VEYS \\ From the Departments of Pathology, Rheumatology, and Gastroenterology, State University Ghent, Belgium, \\ and Lewisham Group Laboratory, Lewisham Hospital, London
}

SUMMARY This study has identified a group of patients with inflammatory chronic, or relapsing acute arthritis who even in the absence of gastrointestinal symptoms have histological evidence of ileocolitis. At colonoscopy simultaneous biopsies of the terminal ileum and colon were taken from 108 patients with reactive arthritis $(n=55)$ or ankylosing spondylitis $(n=53), 47$ patients with other rheumatic diseases and 19 control patients suffering from colonic polyps, adenocarcinoma, or chronic constipation. All control patients and all but one patient with rheumatoid arthritis, juvenile chronic arthritis, systemic lupus erythematosus, lumbar back ache, and psoriatic arthritis did not have histological evidence of acute or chronic inflammatory bowel disease. In contrast, in 30 of 35 $(56.6 \%)$ patients with ankylosing spondylitis, and in 37 of $55(67 \%)$ patients with reactive arthritis, regardless of HLA B27 phenotype, there was histological evidence of inflammatory bowel disease with features either of acute enterocolitis, or early Crohn's disease. Only 18 of $67(27 \%)$ of the patients with histological gut inflammation, however, had intestinal symptoms.

Infections of the urogenital tract and of the intestine are frequent causes of reactive arthritis. Reactive arthritis has been reported after bowel infections with Salmonella typhimurium, ${ }^{1}$ Shigella flexneri, Yersinia enterocolitica ${ }^{3}$ and Campylobacter fetus subspecies jejuni. ${ }^{4}$ In $60-80 \%$ of these patients ${ }^{5}$ HLA $\mathrm{B} 27$ is present.

In the majority of cases of reactive arthritis, however. an infectious agent can not be shown. Arthritis is a frequent extraintestinal feature of inflammatory bowel disease that occurs in $\pm 12 \%$ of cases with ulcerative colitis" and in $\pm 20 \%$ of patients with Crohn's disease.' Histocompatibility locus antigen B27 is not raised in patients with inflammatory bowel disease and peripheral arthritis." It is present in $\pm 2(0-50 \%$ of inflammatory bowel disease patients with axial skeletal involvement" and it is found in $\pm 96 \%$ of cases of ankylosing spondylitis with or without peripheral arthritis." "'

Address for correspondence: Dr ( Cuvelier. N (ioormaghtigh Institute of Pathology. State University of (ihent. De Pintelaan 185. B-9ot)( Ghent. Belgium.

Reccived for publication 2.3 July 19So
Many recent papers concern HLA B27 related unclassifiable reactive arthritis. ${ }^{11-15}$ In previous studies we found evidence of gut inflammation in this group. "In order to assess the possible involvement of the bowel in the pathogenesis of peripheral arthritis of unknown aetiology we undertook an ileocolonoscopic and histopathological study of the terminal ileum, ileocaecal valve, and colon in a larger group of patients.

\section{Methods}

PATIENTS

Ileocolonoscopies have been carried in 108 patients with reactive arthritis $(\mathrm{n}=55)$ and ankylosing spondylitis $(n=53)$ with or without peripheral involvement and in 47 patients with other rheumatic diseases: juvenile rheumatoid arthritis (JCA-type II), rheumatoid arthritis, lumbar back ache or psoriatic arthropathy. All patients gave verbal consent to the ileocolonoscopy and approval of the ethical committee was obtained. Their ages ranged between 12 and 68 years with a mean of 34 years. 
Only 18 patients of the reactive arthritis and ankylosing spondylitis group had ever experienced recurrent diarrhoea, whereas the others never had any gastrointestinal complaints. Stool and lavage fluid cultures were done for all patients on whom ileocolonoscopy was carried out. Most of the enterogenic bacteria, including Klebsiella, were routinely sought but an overgrowth of these bacilli could not be shown. The results were not consistent. Cultures for the major intestinal pathogens, namely Campylobacter jejuni, Campylobacter coli, Salmonella sp, Shigella sp, and Yersinia enterocolitica were systematically done but were negative in all patients. Ileocolonoscopic biopsies taken from 19 patients with unrelated nonrheumatic disease served as histologic controls. The patients had ileocolonoscopy because of polyps, adenocarcinoma or chronic constipation.

The ileocolonoscopic findings were defined as follows: stage (): normal endoscopic findings; stage 1: erythema, oedema, friability of the mucosa; stage 2 : ulcerations, linear or aphthoid; granulation and cobblestoning of the mucosa.

Biopsies were taken blindly in terminal ileum, ileocaecal valve, caecum and colorectum when the mucosa had a normal aspect. They were taken at sites of obvious abnormality when macroscopic lesions were noticed. One to 27 biopsies were studied with a mean of 11 biopsies per ileocolonoscopy.

The tissue was fixed in $10 \%$ formalin or in sublimate-formaldehyde for three to four hours at room temperature. After fixation the biopsies were routinely processed and embedded in paraplast. Tissue sections were cut at $5 \mu \mathrm{m}$ and stained with haematoxylin and eosin.

For working purposes the histopathologic findings were classified into four stages:

\section{Stage 0}

Normal histopathologic findings in terminal ileum, ileocaecal valve and colon.

\section{Stage I}

Lymphoid hyperplasia, increase in chronic inflammatory cell content in the lamina propria with or without

Table 1 Histopathological staging in ileocolonic biopsies of 66 control patients

\begin{tabular}{lcc}
\hline Histopathologicstage & Controls & $R D^{*}$ \\
\hline Stage 0 & 18 & 40 \\
Stage I & 1 & 6 \\
Stage II & 0 & 1 \\
Stage III & 0 & 0 \\
Total & 19 & 47 \\
\hline
\end{tabular}

${ }^{*}$ Other rheumatic diseases: rheumatoid arthritis, rheumatoid arthritis, lumbalgia, psoriatic arthropathy. eosinophilia but no evidence of cryptitis or epithelial abnormalities.

\section{Stage II}

Diffuse increase of inflammatory cells in the lamina propria with partial villous flattening, crypt distortion and reactive hyperplasia of crypt cell epithelium; infiltration of crypt cell epithelium with neutrophils; crypt abscesses.

\section{Stage III}

(Aphthous) ulcerations with or without epithelioid granulomas.

Stage I lesions were considered to be a part of the spectrum of normal terminal ileal histology.

\section{Results}

CONTROLS

All 19 control patients and 47 rheumatic patients with juvenile rheumatoid arthritis type II, rheumatoid arthritis, lumbar back ache or psoriatic arthropathy, showed normal histology in 58 cases or stage I lesions in seven cases. Only one patient with rheumatoid arthritis had histological evidence of mild acute colitis (Table 1).

\section{PATIENTS WITH REACTIVE ARTHRITIS}

Fifty five patients were examined, 27 had stage II and 10 had stage III lesions (Table 2).

The reactive arthritis population was subdivided into 28 HLA B27+ patients and 27 HLA B27, individuals of whom nine patients had sexually acquired reactive arthritis. In the reactive arthritis $\mathrm{B} 27+$ group, 16 of 28 persons had stage II and four of 28 had stage III inflammation. In total, this is $71.4 \%$ of the reactive arthritis $\mathrm{B} 27+$ group. In the reactive arthritis B27- group 14 of 18 patients $(77.7 \%)$ appeared to have histological signs of active inflammatory bowel disease: eight had stage II inflammatory bowel disease and six had stage III lesions. Three

Table 2 Histopathological staging in 108 ileocolonic biopsies of patients with reactive arthritis or ankylosing spondylitis

\begin{tabular}{|c|c|c|c|c|c|c|}
\hline \multirow{2}{*}{$\begin{array}{l}\text { Histo- } \\
\text { pathologic } \\
\text { stage }\end{array}$} & \multicolumn{3}{|c|}{ Reactive arthritis } & \multicolumn{3}{|c|}{ Ankylosingspondylitis } \\
\hline & $B 27+$ & $B 27-$ & Sexaca & $\begin{array}{l}\text { B27+ } \\
\text { without } \\
\text { perarthr }\end{array}$ & $\begin{array}{l}B 27+ \\
\text { with } \\
\text { perarthr }\end{array}$ & $B 27-$ \\
\hline Stage () & 4 & 3 & 6 & 7 & 4 & 1 \\
\hline Stage I & 4 & 1 & () & 3 & 4 & 4 \\
\hline Stage II & 16 & 8 & 3 & 4 & () & 4 \\
\hline Stage III & 4 & 6 & () & 1 & 8 & 4 \\
\hline Total & 28 & 18 & 9 & 15 & 25 & 13 \\
\hline
\end{tabular}

Scx acq: sexually acquired; per arthr: peripheral arthritis. 
patients in the sexually acquired reactive arthritis group $(33.3 \%)$ featured mild acute focal inflammation of the gut wall. They consisted of two heterosexual women and one heterosexual man.

PATIENTS WITH ANKYLOSING SPONDYLITIS Thirty patients of 53 had stage II $(n=17)$ or stage III $(n=13)$ lesions (Table 2). In ankylosing spondylitis $\mathrm{B} 27+$ patients, those without peripheral arthritis showed intestinal inflammation in five of 15 cases $(33.3 \%)$; four had stage II and 1 had stage III inflammatory bowel disease. The ankylosing spondylitis $\mathrm{B} 27+$ patients with peripheral arthritis revealed gut wall inflammation in 17 of 25 cases $(68 \%)$ of whom nine had stage II and eight had stage III disease. Ankylosing spondylitis B27- patients had bowel inflammation in eight of 13 cases $(61.5 \%)$; four had stage II lesions and four featured stage III inflammation.

\section{HISTOPATHOLOGICAL FEATURES}

The histological features of stage II and III lesions are summarised in Tables 3 and 4.

In 37 cases with reactive arthritis and ankylosing spondylitis $(55 \%)$ the inflammation was confined to the terminal ileum and ileocaecal valve. In 25 cases $(37 \%)$ the disease extended into terminal ileum and colon and in five cases $(8 \%)$ the inflammation was confined to the colon only. In 55 of 67 patients the ileal mucosal lesions had the histological features of acute inflammation with or without ulcerations. The

Table 3 Localisation of lesions in the 67 patients with reactive arthritis or ankylosing spondylitis, presenting histological evidence of gut inflammation

\begin{tabular}{lccc}
\hline & Total $(\%)$ & $\operatorname{ReA}$ & $A S$ \\
\hline Terminal ileum ileocaccal valve & $37(55)$ & 22 & 15 \\
Terminal ileum colon & $25(37)$ & 12 & 13 \\
Colon & $5(8)$ & 3 & 2 \\
\hline
\end{tabular}

ReA: Reactive arthritis; AS: ankylosing spondylitis.

Table 4 Histopathologic changes in ileocolonic biopsies of the 67 patients with reactive arthritis or ankylosing spondylitis presenting evidence of gut inflammation

\begin{tabular}{lll}
\hline & Total number & Cases (\%) \\
\hline Type of inflammation & 55 & \\
$\quad$ acute & 12 & 82 \\
$\quad$ chronic & 32 & 18 \\
Microgranulomas & 22 & 48 \\
Lymphangiectasia and oedema & 21 & 33 \\
Epithelial changes & 19 & 31 \\
Ulcers & 14 & 28 \\
Eosinophilic cryptitis & 2 & 3 \\
Sarcoidlike granulomas & & \\
\hline
\end{tabular}

surface epithelium showed infiltration mainly by neutrophils or eosinophils (Fig. 1), and ulceration was present in 19 cases (Fig. 2). The ulcers were covered with fibrin mixed with neutrophils and had an aphthoid appearance in some instances. At the ulcer margin there was evidence of epithelial regeneration. The base of the ulcer was lined by granulation tissue, sometimes covering a hyperplastic lymphoid follicle. In the lymphoid tissue giant cells could be present and in two cases sarcoid-like granulomas without caseation occurred. The ulcerations were with one exception confined to the terminal ileum or ileocaecal valve and were accompanied by ileocolitis or ileitis.

In 12 cases of 67 there was evidence of chronic inflammatory bowel disease. The epithelial changes consisted of partial villus atrophy without significant increase of lymphocytes and crypt distortion in the terminal ileum and ileocaecal valve together with reactive hyperplasia of the crypt cell population featuring regenerative changes (Fig. 3). There was an increased mitotic activity, the cells were crowded and showed pseudostratification, the nuclei were vesicular with prominent nucleoli. The villi showed focal changes such as fusion and blunting and in consequence interepithelial bridging occurred. In two cases pyloric gland metaplasia was present.

In the lamina propria formation of histiocytic microgranulomas was seen in 32 cases. These comprised collections of large histiocytes, loosely or closely aggregated and surrounded by lymphocytes, with some plasma cells and eosinophils. There was no giant cell formation. In some instances the microgranulomas were situated within hyperplastic lymphoid follicles close to the epithelial surface. There were also very superficially located microgranulomas in the lamina propria of the terminal ileum (Fig. 4) and the colon. The adjacent mucosa and submucosa were oedematous and contained lymphangiectatic vessels in 22 cases. The amount of lymphocytes and plasma cells was increased as well as the number of lamina propria eosinophils. The latter tended to be arranged in clusters around crypts and in 14 cases they caused eosinophilic cryptitis and eosinophilic crypt destruction. The affected colonic mucosa showed depletion of mucin and mild infiltration of the crypt epithelium by neutrophils or eosinophils which caused granulocytic or eosinophilic crypt abscesses in some instances. The crypt abscesses featured a crypt covered by flat or partially destroyed epithelium, filled within granulocytes or eosinophils (Fig. 5). There were often histiocytic microgranulomas at the bottom of the destroyed crypts (Fig. 6). The colonic lamina propria was oedematous with areas of sparse cellularity alternating with areas of dense cellularity, composed of plasma cells, 

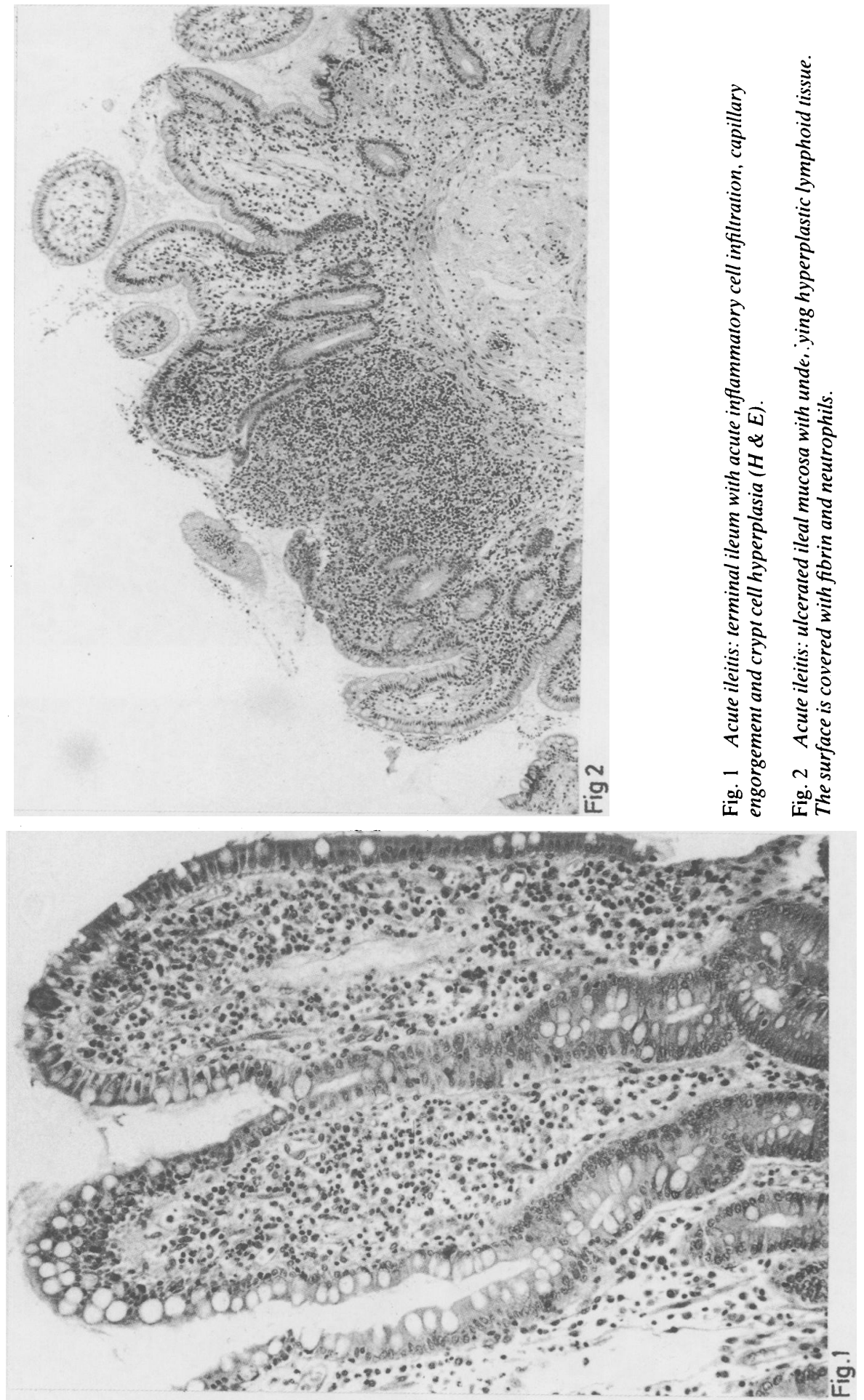


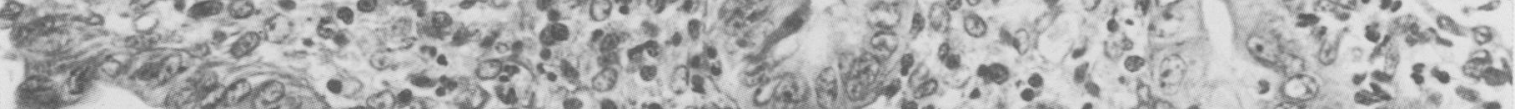

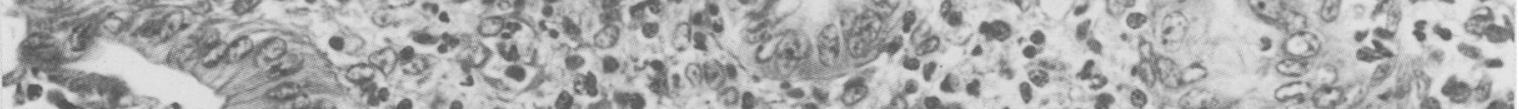

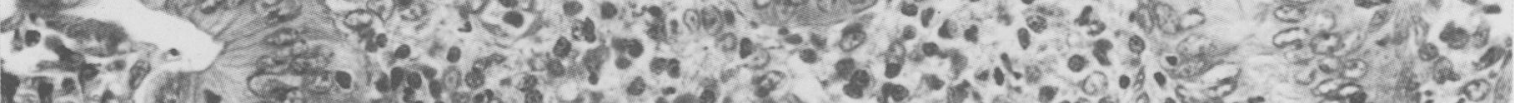
V.P.

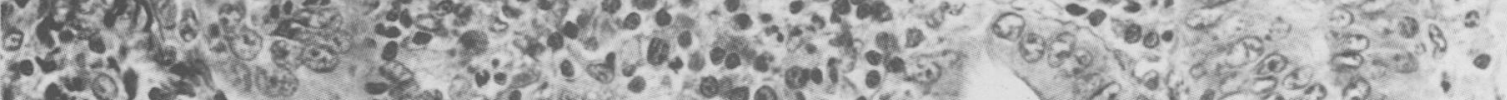

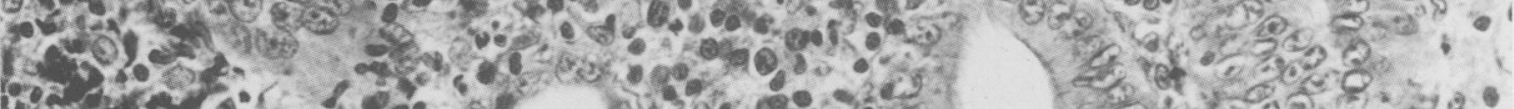

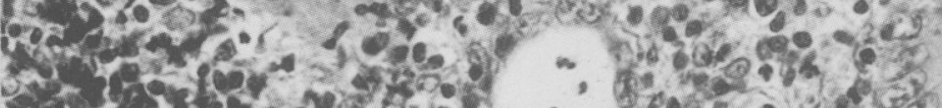

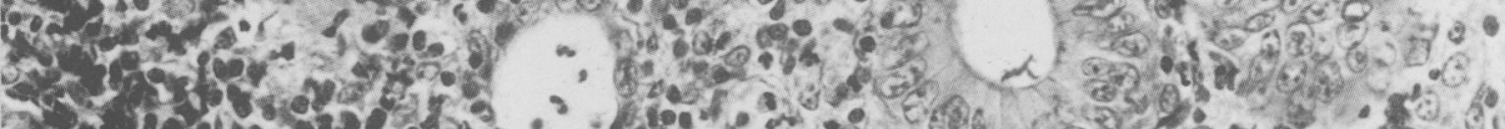

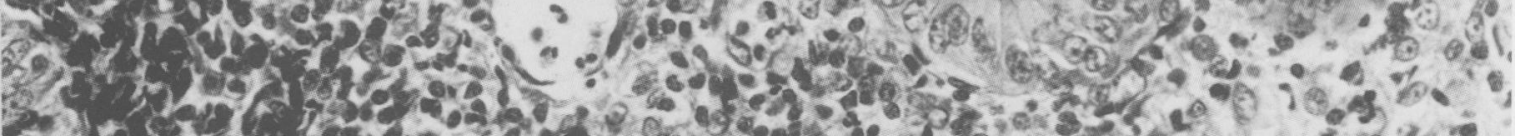

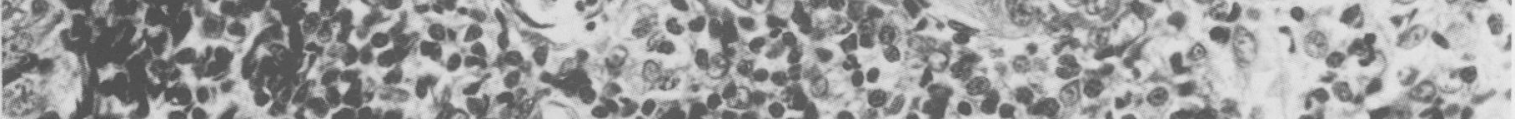

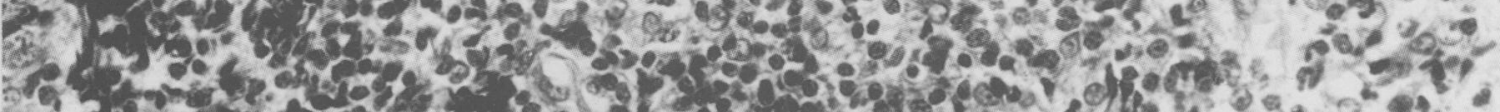

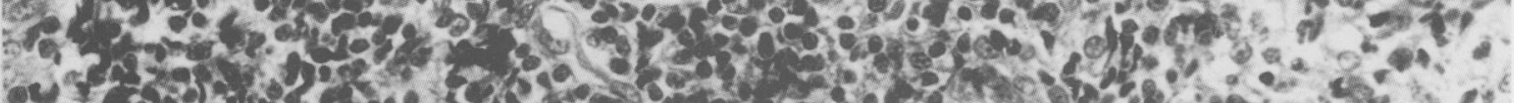

Fig 3

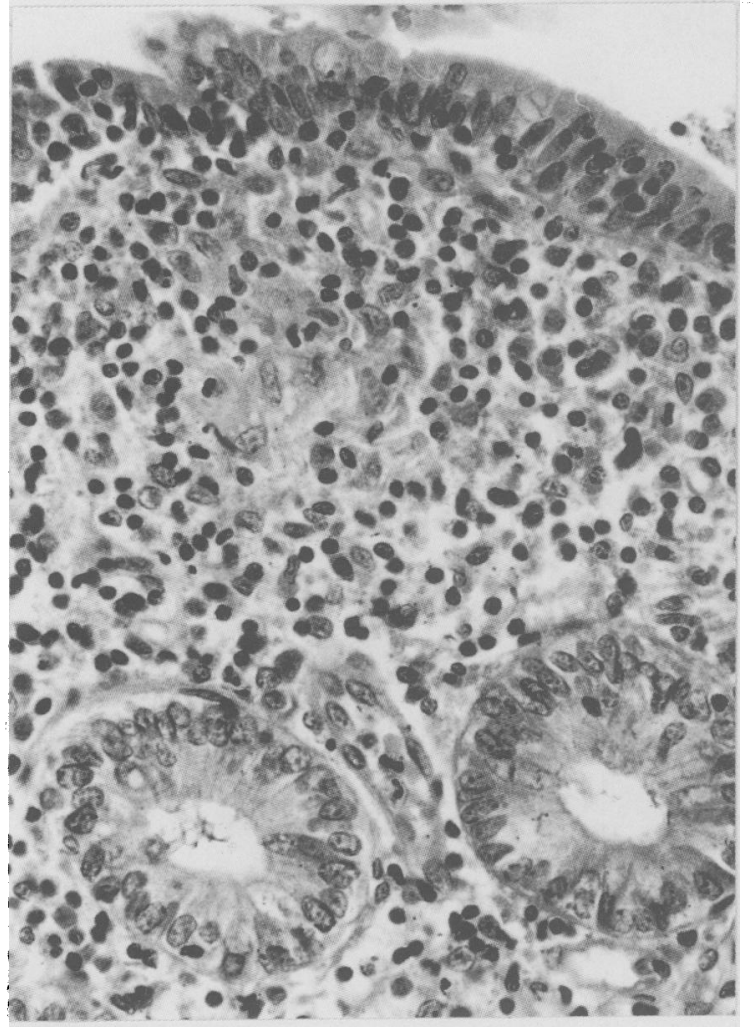

Fig 4

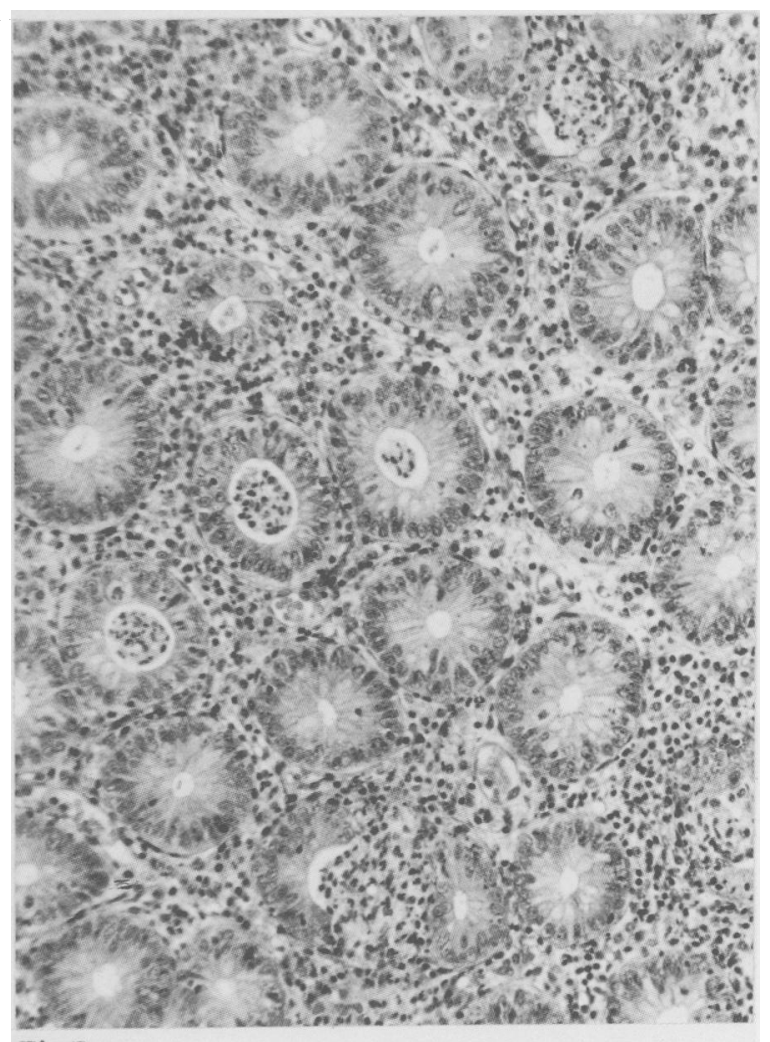

Fig 5

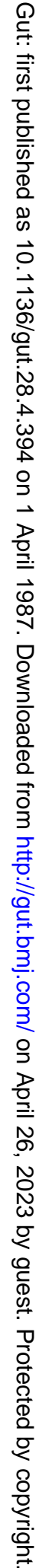


lymphocytes, neutrophils, eosinophils and histiocytes causing a disproportionate inflammation.

\section{Discussion}

This study has shown that a considerable proportion of patients with reactive arthritis and ankylosing spondylitis $(62 \%)$, regardless of HLA B27 phenotype or gastrointestinal symptoms, had evidence of ileitis, ileocolitis or colitis on examination of terminal ileal and colonic biopsies and confirms our earlier observations. ${ }^{16}$

The histopathological features of the asymptomatic bowel wall inflammation are typical either of acute ileocolitis with cryptitis, or chronic inflammatory bowel disease, histologically indistinguishable from early Crohn's disease. The features of acute colitis resembled these described in acute or protracted Campylobacter jejuni colitis. ${ }^{17}$ The latter was indicated by the presence of microgranulomas and in these cases there is an overlap with the spectrum of chronic inflammatory bowel disease. ${ }^{17}$ In our cases, microgranulomas in the superficial part of the lamina propria was a frequent finding, and these are believed to be precursors of granulomas. They are also found in microscopically normal mucosa in Crohn's disease $^{18}$ and can occur in Yersinia enteritis. ${ }^{1921}$ Although there has been an intensive search for causative microorganisms in stool cultures and in serum we have not yet been able to demonstrate (an) infectious agent(s), responsible for the ileocolonic inflammation in our group of patients.

In some cases $(11.5 \%)$ of Yersinia related arthritis, the joint inflammation was not preceded by diarrhoea. El-Maraghi and Mair ${ }^{19}$ described four stages in the course of Yersinia enteritis, namely lymphoid hyperplasia with follicles with large germinal centres, diffuse histiocytic cell hyperplasia, formation of epithelioid cell granulomas with occasional giant cells, and central coagulative necrosis of granulomas with polymorphonuclear cell infiltration and subsequent microabscess formation. In several cases, the histologic findings in the terminal ileum were consistent with Yersinia enteritis, however, with negative serology and with negative clinical findings. Necrotising granulomas and central abscedation were never seen.

Fig. 3 Chronic ileitis: villous flattening and crypt distortion with crypt cell hyperplasia and crypt abscess formation.

Fig. 4 Chronic ileitis with formation of histiocytic microgranuloma in the superficial lamina propria.

Fig. 5 Colonic mucosa with discontinuous inflammatory cell infiltration, crypt cell hyperplasia and numerous crypt abscesses.
The epithelial changes noticed in reactive arthritis related bowel inflammation are usually mild and merely seem to be a sign of crypt and villus destruction and regeneration as a consequence of the acute inflammation rather than an expression of recurrent chronic inflammatory bowel disease. Other cases feature chronic inflammation, with particular similarity to early Crohn's disease and differentiation can be impossible in a few cases, especially when sarcoid-like granulomas are present and epithelial changes occur. Some of the lesions described as 'early' ulcerative lesion of Crohn's disease"' have a similar appearance to those observed in several cases of reactive arthritis related bowel inflammation. Aphthoid ulcers in biopsies from reactive arthritis patients can show the same features with giant cells or granulomas in the underlying hyperplastic lymphoid tissue. The intervillous bridges and blunted villi described in the vicinity of early Crohn's disease lesions have also been observed in the ileal mucosa of patients with reactive arthritis or ankylosing spondylitis.

In isolated cases arthritis can precede the gastrointestinal symptoms of inflammatory bowel disease for several years. ${ }^{22}{ }^{23}$ In our series, however, Crohn's disease could be excluded on clinical grounds as the patients were asymptomatic and routine gastrointestinal investigations (rectal clysma, bowel transit) were within normal limits.

With a ${ }^{51} \mathrm{Cr}$-EDTA (edetic acid) absorption test Bjarnason et $a l^{24}$ showed that the intake of nonsteroidal anti-inflammatory drugs (NSAIDs) increases the permeability of the gut in rheumatoid arthritis patients. In our study group, most patients with reactive arthritis and ankylosing spondylitis were taking NSAIDs, mainly pyroxicam, indomethacin or phenylbutazone. A small number of these patients (six of 108) were not treated with NSAIDs before the ileocolonoscopy was carried out. Five of these six patients, however, featured bowel wall inflammation on biopsy. In contrast, practically all patients with juvenile rheumatoid arthritis, rheumatoid arthritis, and psoriatic arthritis were treated with the same NSAIDs but they did not, except one patient with rheumatoid arthritis, show gut inflammation on biopsy.

Our study has identified a group of arthritis patients suffering from acute or chronic ileocolitis. Hence it is possible to distinguish, in the spectrum of arthritis related bowel inflammation, a group with bacteria induced enterocolitis, ${ }^{1-1}$ a group with chronic idiopathic inflammatory bowel disease,,$^{(-\infty}$ and a group with a hitherto unrecognised type of relapsing acute or chronic enterocolic inflammation caused by leaking of food or enterobacterial antigens across a more permeable mucosa which could initiate and sustain local and systemic inflammation. 


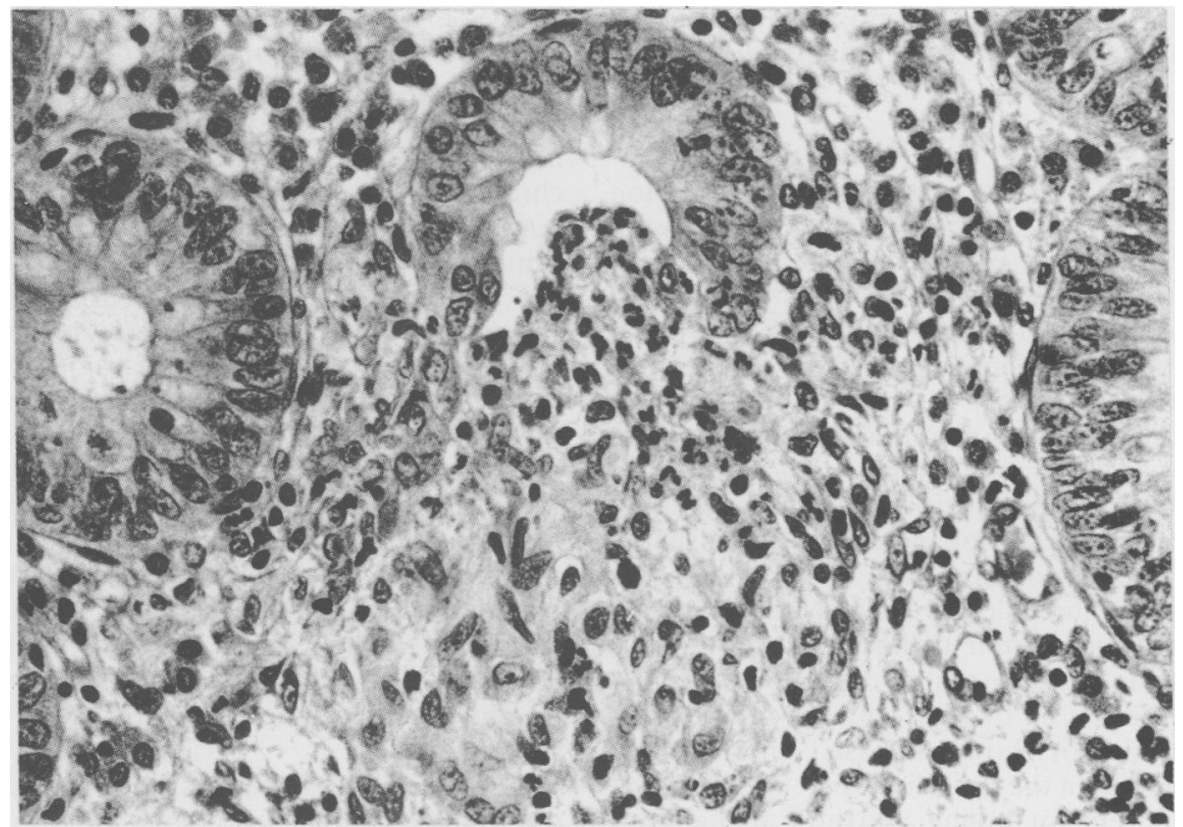

Fig. 6 Colonic crypt abscess with microgranuloma at the bottom of a destroyed crypt.

Further immunohistochemical and bacteriological studies are required in order to investigate whether the described changes in terminal ileum and colon are a localised immune response to antigens in the bowel wall causing recurrent acute inflammation or Crohn's disease like lesions, a manifestation of selflimiting inflammation like bacterial enterocolitis or early asymptomatic Crohn's disease.

\section{References}

1 Warren CPW. Arthritis associated with salmonella infections. Ann Rheum Dis 1970; 29: 483-7.

2 Moer HR. An 'experimental epidemic' of Reiter's syndrome. JAMA 1966; 198: 693-8.

3 Aho K, Ahvonen P, Lassus A, Sievers K, Tiilikainen A. HLA-B27 in reactive arthritis. A study of yersinia arthritis and Reiter's disease. Arthritis Rheum 1974; 17: 521-6.

4 Berdun JH, Muyntjens HL, Van de Putte LB. Reactive arthritis associated with campylobacter jejuni enteritis. Br Med J 1979; 1: 380)-1.

5 Keat A. Reiter's syndrome and reactive arthritis in perspective. N Engl J Med 1983; 309: 1606-15.

6 Wright $\mathrm{V}$, Watkinson $\mathrm{G}$. The arthritis of ulcerative colitis. Br Med J 1965; 2: 670-80.

7 Haslock I, Wright V. The musculo-skeletal complications of Crohn's disease. Medicine 1973; 52: 217-25.

8 Morris RI, Metzger AL, Bluestone R, Terasaki PI. HLA-W27 - A useful discriminator in the arthropathies of inflammatory bowel disease. N Engl J Med 1974; 290: 1117-19.

9 Brewerton DA, Hart FD, Nicholls A, Caffrey M, James DCO, Sturrock RD. Ankylosing spondylitis and HLAW27. Lancet 1973; i: 904-7.

10 Schlosstein L, Terasaki PI, Bluestone R, Pearson CM. High association of an HLA antigen, W27, with ankylosing spondylitis. N Engl J Med 1973; 288: 704-6.

11 Bitter T, Jeannet E, de Haller E, Lejeune M. Persistent yet reversible asymmetric pauciarthritis: a B27 associated cluster. Ann Rheum Dis 1979; suppl. 38: 84-91.

12 Joliat G, Penro A, Jeannet M, Ott H. HLA-B27 antigen in diagnosis of atypical seronegative inflammatory arthropathy. Ann Rheum Dis 1976; 35: 531-3.

13 Eastmond CJ, Rayah SM, Tovey D, Wright V. Seronegative pauciarticular arthritis and HLA-B27. Ann Rheum Dis 1980; 39: 231-4.

14 Meyer O, Vignolli M, Ryckewaert A. Rhumatismes inflammatoires inclassables avec HLA-B27. Rev Rhum Mal Osteoartic 1982; 49: 11-16.

15 Prakash S, Mehra NK, Bhancava S, Malaviya AN. HLA-B27 related 'unclassifiable' seronegative spondyloarthropathies. Ann Rheum Dis 1982; 42: 640-3.

16 Mielants $H$, Veys E, Cuvelier C, De Vos $M$, Botelberghe L. HLA-B27 related arthritis and bowel inflammation. Part 2. Ileocolonoscopy and bowel histology in patients with HLA-B27 related arthritis. J Rheumatol 1985; 12: 293-8.

17 Van Spreeuwel JP, Duursma GG, Meijer CJLM, Bax R, Rosekrans PCM, Lindeman J. Campylobacter colitis: Histological, immunohistochemical and ultrastructural findings. Gut 1985; 26: 945-51. 
18 Rotterdam H, Korelitz BI, Sommers SC. Microgranulomas in grossly normal rectal mucosa in Crohn's disease. Am J Clin Pathol 1977; 67: 550-4.

19 El-Maraghi NRH, Mair NS. The histopathology of enteric infection with Yersinia pseudotuberculosis. Am J Clin Pathol 1979; 71: 631-9.

20 Vantrappen G, Agg HO, Ponette E, Geboes K, Bertrand TH. Yersinia enteritis and enterocolitis. Gastroenterology 1977; 72: 220-7.

21 Rickert RR, Carter HW. The 'early' ulcerative lesion of Crohn's disease: correlative light- and scanning electron-microscopic studies. J Clin Gastroenterol 198(); 2: $11-19$.

22 Smith MC, Barker JD. Granulomatous ileocolitis preceded by three years of pauci- articular arthritis. $\mathrm{Am}$ J Gastroenterol 1978; 69: 328-30.

23 Haslock I. Arthritis and Crohn's disease. Ann Rheum Dis 1973; 32: 479-86.

24 Bjarnason I, So A, Levi AJ, et al. Intestinal permeability and inflammation in rheumatoid arthritis: effects of nonsteroidal anti-inflammatory drugs. Lancet 1984; ii: 1171-4. 